\title{
GUEST EDITORS' NOTE
}

In the pragmatics literature there is no consensus concerning the subject of the field. One can find various treatments of pragmatics that differ from each other, e.g., in respect of how pragmatics is related to grammar and semantics, or to code use, communication and cognition; whether the phenomena studied by pragmatics belong to competence or performance; whether the pragmatic abilities of the human mind may be considered a module, and if so, how this module could be characterized. (For an overview of pragmatics conceptions, traditions and methods, see Jef Verschueren, The pragmatic perspective. In: Jef Verschueren-Jan-Ola Östman-Jan Blommaert (eds): Handbook of pragmatics: Manual. 1995, 1-19. Benjamins, Amsterdam.)

In the papers presented here about pragmatics and in a further, second instalment of this thematic issue, which will be published in the next volume of Acta Linguistica Hungarica, one can also see the different strands. Hence, there is only a general "common denominator" valid for all contributions: Pragmatics deals with the use of language in various contexts to achieve various purposes, primarily from a linguistic point of view.

The diversity of the present papers and pragmatics itself is increased by the fact that phenomena of language use are the subject of several other disciplines: social psychology, sociolinguistics, rhetoric, stylistics, etc. Indeed, these fields amplify our knowledge about issues of language use. In addition, pragmatics, in accordance with its theory-dependent scope of interest, strives to advance aided by these disciplines and integrate their achievements. From among the disciplines studying language use, discourse analysis merits a separate mention. Very often, it is demarcated from pragmatics only because of its own name, which, however, can refer to a wide range of topics such as analysis of oral discourses and written texts as well as conversation analysis, discourse and text grammar.

The first aim of this special issue, i.e., the present and forthcoming collections of papers, is to show the diversity (in the above-mentioned senses) characteristic of present-day Hungarian pragmatics research. The

second aim of the two instalments is to provide up-to-date investigations which apply the theoretical and interdisciplinary approaches to several kinds of pragmatic phenomena in Hungarian. The editors think that each 
paper contributes this way to the further development of theoretical issues and/or description of pragmatics of Hungarian language use.

Turning to a brief overview of the papers included in this first instalment of the thematic issue of Acta Linguistica Hungarica, we have to begin with a remark concerning the arrangement of the papers. The diversity of perspectives and aspects appearing in contributions has made it impossible to place them in some thematic order. Therefore, the articles are arranged alphabetically by their authors' names. The topics of the papers will also be introduced below in this order but we will attempt to indicate some interconnections between them.

In her paper entitled Pragmatic aspects of persuasion and manipulation in written advertisements, Anett Árvay attempts, first, to separate persuasion from manipulation in an interdisciplinary - pragmatic and social psychological - framework and identifies four possible types of manipulation. Then, in the second part of the paper she investigates how persuasion and manipulation work in written advertisements in Hungarian. And finally, a Hungarian and an American direct mail message are analysed to see whether the revealed Hungarian strategies exist in English or not, i.e., whether they are language-specific or not.

Károly Bibok's paper Word meaning and lexical pragmatics outlines a conception of lexical pragmatics which critically amalgamates the views of Two-level Conceptual Semantics, Generative Lexicon Theory and Relevance Theory and has more explanatory power than each theory does separately. Such a lexical pragmatic conception accepts lexical-semantic representations which can be radically underspecified and allow for other methods of meaning description than componential analysis. As words have underspecified meaning representations, they reach their full meanings in corresponding contexts (immediate or extended) through considerable pragmatic inference. The Cognitive Principle of Relevance regulates the way in which the utterance meaning is construed.

István Kecskés's contribution The role of salience in processing pragmatic units explains the relevance of Giora's Graded Salience Hypothesis to pragmatics research, arguing that although this hypothesis is a psycholinguistic theory, it may contribute significantly to our understanding of pragmatic processing. It is claimed that the salient meaning of lexical units constituting utterances in conversation plays a more important role in comprehension than has been believed by supporters of the direct access view, the classic modular view, Two-level Conceptual Semantics and Relevance Theory.

In his paper Morphopragmatic phenomena in Hungarian Ferenc Kiefer discusses pragmatic aspects of patterns created by morphological rules. 
The first phenomenon considered concerns the use of the excessive which does not add semantic information to the superlative and carries purely pragmatic information only. The second problem investigated has to do with the pragmatics of the diminutive suffix. The semantic meaning of the diminutive suffix is 'small' or 'a little', which is often overridden by the pragmatic meaning. The third phenomenon is the possibility suffix -hat/ -het. From among its various pragmatic meanings deontic speech acts are well-known from other languages. There are, however, several other uses of this suffix which seem to be typical of Hungarian.

Attila László Nemesi in his article What discourse goals can be accomplished by the use of hyperbole? looks at the role of hyperbole in interpersonal rhetoric, using conversations from classic Hungarian films as data. Analyses demonstrate that hyperbolic utterances convey the speakers' attitudes, either real or only presented, towards the topic of conversation. According to the social psychological laws of public behaviour, the expression of emotional relation or attitude is mostly subordinated to the speaker's attempt to construct an intended impression on conversational partners.

The contribution The principles of communicative language use by Enikő Németh T. overviews some typical principles of communicative language use in a cognitive pragmatic approach applying a reductionist method. It re-evaluates the principles and provides a new classification of them relying on the definition of ostensive-inferential communication. The principles which can be divided into rationality and interpersonality principles are really principles of effective information transmission on objects and selves. They refer to two kinds of language use: informative and communicative ones. Finally, the paper reduces all rationality and interpersonality principles to a very general rationality principle, i.e., the cognitive principle of relevance.

$$
* * *
$$

The guest editors would like to express their gratitude, first of all, for the opportunity given to them by the editor-in-chief of Acta Linguistica Hungarica, and for the assistance of the associate editor. All the papers were refereed by at least two reviewers, to whom we wish to express our special thanks at this place. Finally, we are grateful to the contributors for their commitment and patience during the refereeing and editing process.

Enikő Németh T., Károly Bibok 